\title{
Methods of Outcomes Measurement in Nail Psoriasis
}

\author{
M. Augustin ${ }^{a} \quad$ A. Ogilvie ${ }^{b}$
}

${ }^{a}$ Center for Health Services Research in Dermatology (CVderm), Department of Dermatology, University Clinics of Hamburg, Hamburg, and b ${ }^{\text {P }}$ soriasis Clinic, Department of Dermatology, University Clinics of Erlangen, Erlangen, Germany

\section{Key Words}

Nail psoriasis · Assessment tools • Psoriasis

\begin{abstract}
Background: Nail involvement is a common feature of psoriasis, predicting higher disease severity and greater impairment in quality of life. Valid assessment of nail psoriasis is relevant for research and routine clinical use. However, no measurement standards have currently been developed. Objective: To identify state-of-the-art outcomes measurements in nail psoriasis by literature analysis. Methods: Systematic Web-based literature search, followed by structured critical appraisal and consecutive descriptive report. The search focused on methodological and epidemiological publications and papers describing outcomes of clinical trials on nail psoriasis. Results: Initially, 646 publications met the primary criteria. After non-relevant or replicate publications were excluded, 66 papers were analysed, including clinical trials or case reports $(n=41)$, reviews $(n=11)$ and methodological or epidemiological studies $(n=14)$. In total, 23 clinical outcomes measures and 15 patient-reported outcomes (PRO) tools were used. None had been validated according to recent standards. In the studies with clinical interventions ( $n=41$ ), NAPSI (Nail Psoriasis Severity Index; $n=4$ ) or target NAPSI $(n=2)$ were the most often used single tools,
\end{abstract}

followed by Physician's Global Assessment $(n=3)$. However, in 16 studies, no specifically described outcomes measures were used. Conclusion: Valid clinical outcomes measures in nail psoriasis are rare. Existing tools lack validation and standardisation. A need exists for accurate and scientifically sound evaluation of nail psoriasis severity in trials and clinical practice. To cover all elements of nail psoriasis, the optimal nail psoriasis assessment tool would include both PRO and physician-assessed outcomes measures.

Copyright $\odot 2010$ S. Karger AG, Basel

\section{Introduction}

With a prevalence of $2-3 \%$, psoriasis vulgaris is one of the most common chronic skin diseases $[1,2]$. Due to the serious impairments in quality of life caused by the usually chronic and often refractory course of disease, psoriasis is of considerable socioeconomic relevance $[3,4]$. Additionally, different types of diseases are associated with psoriasis. For example, there is a distinct pattern of enthesitis, osteitis and synovitis that is generally referred to as psoriatic arthritis (PsA) [5-7]. Recent data from two distinct trials suggest that approximately $20 \%$ of German patients visiting a dermatologist for psoriasis have PsA [8, 9]. Moreover, in approximately $85 \%$ of these cases, PsA

\section{KARGER \\ Fax +4161306 1234 \\ E-Mail karger@karger.ch}

www.karger.com
C) 2010 S. Karger AG, Basel

$1018-8665 / 10 / 2215-0023 \$ 26.00 / 0$

Accessible online at: www.karger.com/drm
Prof. Dr. med. Matthias Augustin, MD

Center for Health Services Research in Dermatology (CVderm)

Department of Dermatology, University Clinics of Hamburg

Martinistrasse 52, DE-20246 Hamburg (Germany)

Tel. +494042803 5428, Fax +494042803 5348, E-Mail m.augustin@ derma.de 
was newly diagnosed, even with previous complaints of joint problems [8]. Several studies have also demonstrated that patients with psoriasis can have an increased risk of developing comorbidities related to the metabolic syndrome $[2,10]$. The most frequent association of psoriasis and concomitant disease, however, is found with nail psoriasis. Variable prevalence data demonstrate that up to $50 \%$ of patients with psoriasis have concurrent nail psoriasis [11-13]. In patients with moderate to severe psoriasis, approximately $82 \%$ have symptoms of nail psoriasis [14]; up to $5 \%$ of patients have nail psoriasis alone [11-12]. In most cases, a diagnosis of nail psoriasis is established according to clinical criteria; thus, it is important to examine the complete integument to understand its burden on the patient.

Evaluating the severity of nail involvement in psoriasis remains challenging. A variety of systems have been established to evaluate nail psoriasis, including Baran's nail psoriasis severity index [15], Cannavò's scoring system [16] and the nail psoriasis quality of life scale (NPQ10) [17]. The Nail Psoriasis Severity Index (NAPSI) is a reproducible, objective and simple tool for the clinical assessment of psoriatic nail disease and is the only clinical scale that has been validated [18]. As with other tools, the NAPSI has limitations in terms of sensitivity and exclusion of types of changes and degree of severity $[18,19]$. Moreover, nail psoriasis can cause both physical and psychological impairments that significantly reduce health-related quality of life (HRQoL) [13]. For these reasons, any assessment of nail psoriasis severity should include HRQoL parameters from the patient's perspective. To date, none of the existing assessment tools for nail psoriasis address both objective and patient-reported parameters.

Only recently, publications have focused on the question of validity and feasibility in outcomes measurements of nail psoriasis [20-23]. The objective of this study was to identify state-of-the-art outcomes measurements of nail psoriasis by a literature search.

\section{Methods}

\section{Study Design}

The study was designed as a literature review of publications based on a protocol-driven search of online databases with a concurrent consecutive manual search. The literature search was completed by July 2009. Data analysis was descriptive and was performed by CVderm. All databases were searched from their inception to the date of the search. Searches were also undertaken of several Internet-accessible data sources (fig. 1). The bibliographies of all publications were reviewed to identify further relevant studies. Hand-searching continued throughout the project. The
- MEDLINE and In-Process Citations (PubMed Online) (http://www.ashburypress.com/medline/resources/in-process. html)

- EMBASE (Ovid Online) (http://www.ovid.com/site/products/ovidguide/embase.htm)

- Cochrane Central Register of Controlled Trials (CENTRAL) (http://uscc.cochrane.org/en/index.html)

- CenterWatch (http://www.centerwatch.com/)

- Current Controlled Trials (http://controlled-trials.com/)

- ClinicalTrials.gov (http://clinicaltrials.gov/)

- NHS Economic Evaluation Database (NHS EED) (CRD administration database) (http://www.crd.york.ac.uk/ crdweb/Home.aspx?DB=NHS\%20EED)

- EconLit (SilverPlatter on the Web) (http://www.accessmylibrary.com/web-econlit-silverplatter.html)

- ISI Science and Technology Proceedings (http://wos.mimas.ac.uk/)

- Social Sciences Citation Index (http://wos.mimas.ac.uk/)

- Science Citation Index (http://wos.mimas.ac.uk/)

Fig. 1. Internet search databases used in the literature search.

terms for the search strategies were identified through discussion between two Cochrane specialists from CVderm and the authors (M.A., A.O.) by scanning the background literature and several health technology assessment reports on psoriasis and by browsing the MEDLINE thesaurus (MeSH). The systematic search of PubMed was performed as described in figure 2.

\section{Study Selection}

Two reviewers (M.A., A.O.) independently selected the studies for review based on the paper titles and abstracts. Discrepancies were resolved by consensus, and a third reviewer was consulted if necessary. Studies reported as full publications or unpublished full reports were included in the review. Studies reported as abstracts were included only if adequate information was provided. All titles and abstracts identified by the search were screened, and any references that were considered relevant by either reviewer were obtained. No language or other restrictions were applied. Only publications that included specific information on the use of instruments for the diagnosis or assessment of nail psoriasis were considered.

\section{Critical Appraisal}

The included publications were analysed according to a structured protocol and transferred into a predesigned Excel form. The criteria for analysis referred to the following questions:

- Are there any publications on the methodology of outcomes measurement in nail psoriasis, and if yes, are there any validation data on these methods?

- Which outcomes parameters are used in clinical trials on nail psoriasis?

- Which parameters were used in studies on epidemiology of nail psoriasis? 


\section{Data Extraction Strategy}

All data were extracted by one reviewer and independently checked for accuracy by the second reviewer. Disagreements were resolved through consensus and by consultation with a third reviewer if necessary. Data from studies with multiple publications were extracted and reported as from a single study. The following details were extracted from each trial (if applicable):

- Study details (author, year, country, type of publication, other publications/reports, study design, setting, duration of trial follow-up, frequency of follow-up, sample size calculation, analyses).

- Participant details (number randomised and treated, age, gender, psoriasis history, duration of psoriasis and nail psoriasis, proportion of patients with nail affection).

- Clinical characterisation of patients, e.g. Psoriasis Area and Severity Index, Dermatology Life Quality Index (DLQI), body surface area at baseline.

- Details of outcomes measurements.

Assessment of Study Quality

The quality of trials was assessed by one reviewer and independently checked by a second reviewer. Disagreements were resolved through consensus, and a third reviewer was consulted if necessary.

\section{Efficacy Trials}

The efficacy trials were assessed for quality using a checklist compiled from criteria specified in the methodology of the German Federal Joint Committee (Gemeinsamer Bundesausschuss). The quality of each study was summarised as a quality rating, classifying trials as excellent, good, satisfactory or poor.

Epidemiological Studies and Economic Evaluations

Data were extracted into a quality assessment template, covering selection of alternatives, treatment of costs and benefits (including any modelling undertaken), use of discounting, allowance for uncertainty and presentation of results. The checklist is an updated version of that developed by Drummond et al. [24].

\section{Results}

\section{Systematic Literature Search}

Based on the strategy outlined above, 104 publications were found that included the combination of nail psoriasis and outcomes measurement (fig. 3). Thirty-eight publications had to be excluded for the following reasons: irrelevant for research questions, replicate publications and no outcomes measured. Sixty-six publications were selected for analysis (table 1). These included 41 clinical publications and 25 publications without clinical data collection. The latter consisted of 11 reviews and 14 methodological or epidemiological studies. The clinical publications included 27 clinical trials and 14 other publications addressing clinical outcomes.

Methods of Outcomes Measurement in Nail Psoriasis

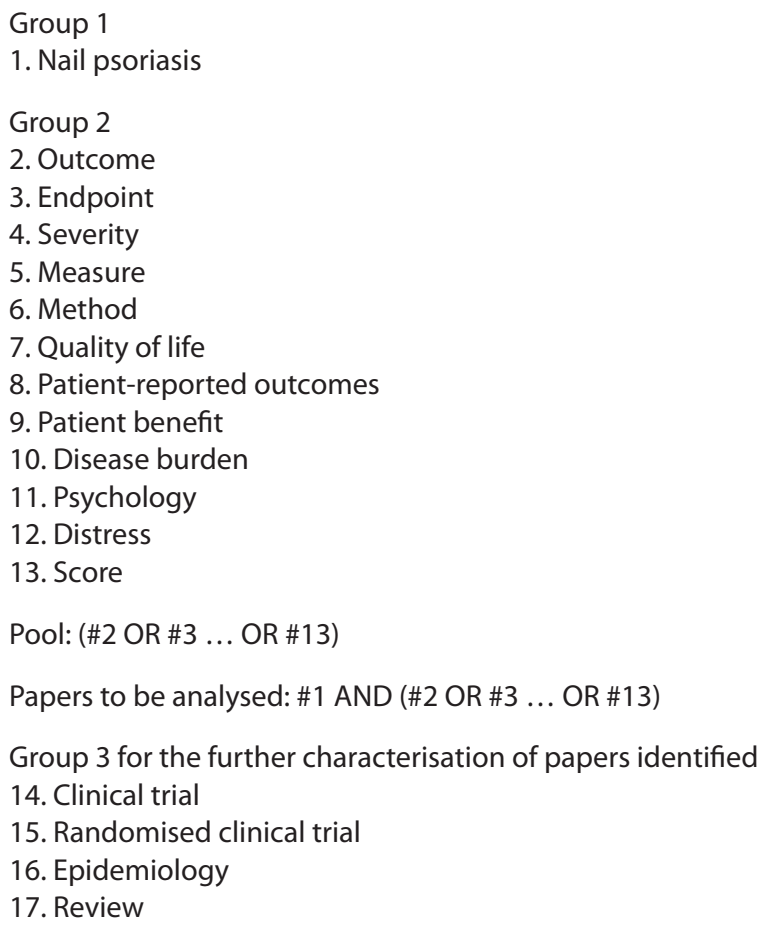

Fig. 2. Systematic search of PubMed.

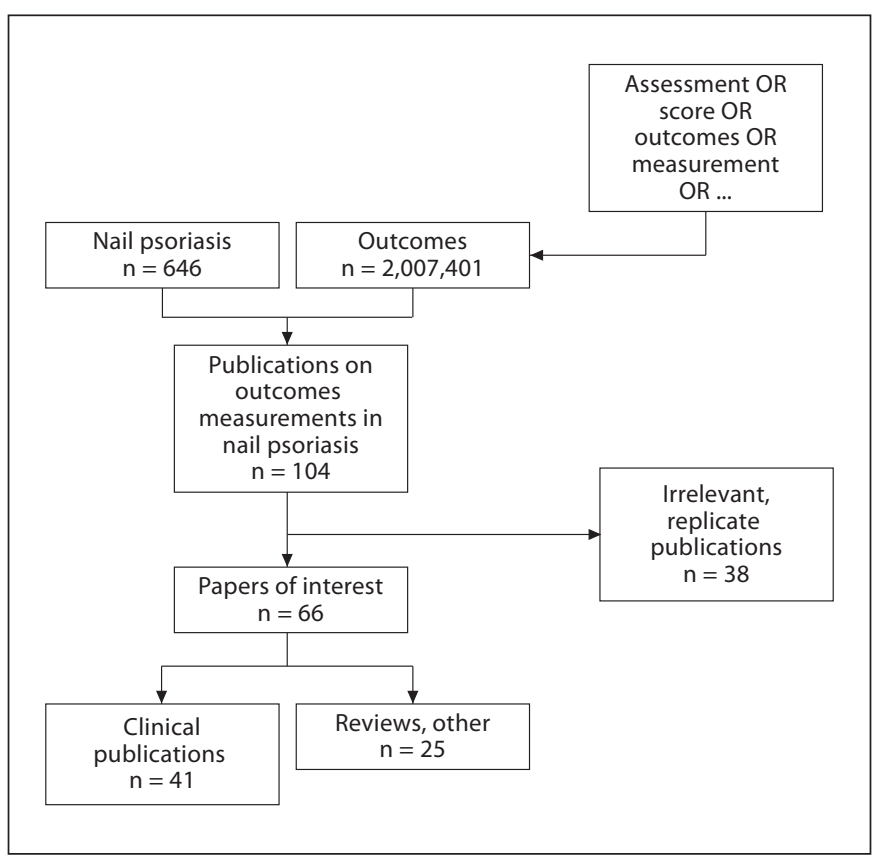

Fig. 3. Results of the literature search on nail psoriasis and outcomes measures.

Dermatology 2010;221(suppl 1):23-28 
Table 1. Publications regarding the epidemiology of nail psoriasis or the methodology of nail psoriasis outcomes measurement

$\begin{array}{lr}\text { Clinical trials } & \\ \text { Uncontrolled clinical trials } & 9 \\ \text { Randomised controlled trials } & 10 \\ \text { Non-randomised controlled trials } & 8 \\ \text { Total } & 27 \\ \text { Treatment evaluations } & \\ \text { Retrospective data analyses } & 5 \\ \text { Non-interventional studies } & 7 \\ \text { Safety trials } & 0 \\ \text { Case studies } & 2 \\ \text { Total } & 14 \\ \text { Nonclinical publications } & \\ \text { Literature review } & 7 \\ \text { Systematic review } & 4 \\ \text { Methodological study } & 2 \\ \text { Epidemiological survey } & 1 \\ \text { Other } & 11 \\ \text { Total } & 25 \\ \text { Total publications } & \\ \text { Clinical trials } & 27 \\ \text { Treatment evaluations } & 14 \\ \text { Non-clinical publications } & 25 \\ \text { Total } & 66\end{array}$

\section{Outcomes Tools in Epidemiological and \\ Methodological Studies}

In the literature search, $3 \%(2 / 66)$ of the publications selected covered the methodology of nail psoriasis evaluation. These publications included the development of instruments for nail assessment. However, these assessments were not based on international standards of test development but were performed on a clinical basis.

\section{Outcomes Tools in Clinical Trials}

In the clinical trials, a total of 9,388 patients were observed (table 2). Since the clinical characteristics in the trials are subject to selection bias, no epidemiological conclusions from the data can be drawn. Regarding the clinical publications, there were two instruments mentioned that specifically evaluated the clinical severity of nail psoriasis: the NAPSI $(n=4)$ or target NAPSI $(n=2)$, and Cannavò's score $(\mathrm{n}=1)$. In the review another severity score was named, nail area severity score, but not indicated as used. However, in most clinical studies and in the case reports, no specific instruments for the assessment of patient-reported outcomes (PRO) were found $(\mathrm{n}=14)$. PRO were measured in $24 \%(10 / 41)$ of the
Table 2. Characteristics of nail psoriasis in the clinical publications $(\mathrm{n}=41)$

\begin{tabular}{lrcc}
\hline & $\begin{array}{l}\text { Clinical } \\
\text { trials }\end{array}$ & $\begin{array}{l}\text { Treatment } \\
\text { evaluations }\end{array}$ & $\begin{array}{l}\text { All clinical } \\
\text { publications }\end{array}$ \\
\hline Publications & 27 & 14 & 41 \\
Patients & 2,824 & 6,564 & 9,388 \\
Nail Pso patients, \% & 87.4 & 69.4 & 76.5 \\
History of psoriasis, years & 14.9 & 14.1 & 14.4 \\
History of Nail Pso, years & 10.0 & NA & 10.0 \\
PsA patients, total, \% & 54.0 & 43.3 & 44.5 \\
PsA among Nail Pso, \% & 4.0 & 73.6 & 68.2 \\
Mean age, Nail Pso, years & 50.9 & 37.3 & 42.7 \\
Mean age, no Nail Pso, years & 48.6 & 33.3 & 32.9 \\
Male patients, Nail Pso, \% & 77.4 & 51.7 & 65.7 \\
Male patients, no Nail Pso, \% & 11.5 & 76.6 & 49.4 \\
\hline
\end{tabular}

PsA = Psoriatic arthritis; Nail Pso = nail psoriasis

studies. In these cases, disease-specific, but not condition-specific, quality of life instruments were used. Surprisingly, data on DLQI were not reported in any of the publications.

In total, 14 clinical trials were identified that assessed nail psoriasis under treatment (table 3). Nine of these trials focused directly on nail psoriasis; the others looked at psoriasis in general $(n=4)$ or at several indications $(\mathrm{n}=1)$.

\section{Discussion}

The present investigation was performed to obtain an overview of outcomes instruments used in nail psoriasis. Clinical outcomes studies as well as methodological or epidemiological studies were included. A total of 66 publications met the inclusion criteria, indicating that outcomes assessments in nail psoriasis have not yet been frequently performed. The number of clinical trials with a specific focus on nail psoriasis is low. Moreover, only a few publications addressed the question of valid measurement for nail psoriasis, though some have explored the correlation between instruments. For example, EXPRESS (European Infliximab for Psoriasis [Remicade $^{\circledR}$ ] Efficacy and Safety Study) demonstrated that the number of nails involved and target nail NAPSI scores correlated significantly at baseline and during treatment 
Table 3. Outcomes measures used in the clinical studies $(n=41$ publications)

\begin{tabular}{lrcc}
\hline & $\begin{array}{c}\text { Clinical } \\
\text { trials }\end{array}$ & $\begin{array}{l}\text { Treatment } \\
\text { evaluations }\end{array}$ & $\begin{array}{l}\text { All clinical } \\
\text { publications }\end{array}$ \\
\hline Publications & 27 & 14 & 41 \\
Total patients & 2,824 & 6,564 & 9,388 \\
Patients per study, mean & 157 & 298 & 232 \\
Clinical scores on nail psoriasis & 15 & 11 & 26 \\
Total NAPSI & 3 & 1 & 4 \\
Target NAPSI & 0 & 2 & 2 \\
Cannavò & 1 & 0 & 1 \\
NAS & 0 & 0 & 0 \\
Other score & 7 & 7 & 14 \\
Nail count & 1 & 1 & 2 \\
PGA dyn & 1 & 0 & 1 \\
PGA stat & 2 & 0 & 2 \\
Patient-reported outcomes & 7 & 3 & 10 \\
PatGA dyn & 2 & 0 & 2 \\
PatGA stat & 3 & 1 & 4 \\
Burden of disease & 1 & 0 & 1 \\
QoL - DLQI & 0 & 0 & 0 \\
QoL - other & 1 & 2 & 3 \\
\hline
\end{tabular}

DLQI = Dermatology Life Quality Index; NAPSI = Nail Psoriasis Severity Index; NAS = nail area severity score; PatGA $=\mathrm{Pa}$ tient's Global Assessment; PGA = Physician's Global Assessment; QoL = quality of life. with infliximab [25]. Although some correlations may exist, none of the instruments used in any of the trials meet the criteria for outcomes measurement as required, for example, by the German national guidelines [26]. Additionally, no comprehensive PRO measurements specific to nail psoriasis have yet been validated, though a recent publication on nail QoL outcomes measurement demonstrates initial progress [17]. However, the data collected in this review indicate that no specific assessment tools address all disease aspects, including nail severity and the impact of nail psoriasis on HRQoL. As a result, the impact of nail disease in a psoriasis patient may be inadequately measured or underestimated. There is a definite need for more methodological developments in nail psoriasis assessment. A more feasible tool is needed that can serve as an individual measurement of treatment outcomes in clinical trials and also address the importance of adequately evaluating the impact of nail psoriasis on a patient's quality of life in routine practice.

\section{Conflicts of Interest}

M. Augustin and A. Ogilvie serve as consultants for Schering Corporation, a subsidiary of Merck \& Co., Inc. Editorial support for the development of this publication was provided by Schering Corporation, a subsidiary of Merck \& Co., Inc.

\section{References}

1 Schäfer I, Rustenbach SJ, Zimmer L, Augustin M: Prevalence of skin diseases in a cohort of 48,665 employees in Germany. Dermatology 2008;217:169-172.

2 Augustin M, Reich K, Glaeske G, Schaefer I, Radtke M: Comorbidity and age-related prevalence of psoriasis: analysis of health insurance data in Germany. Acta Derm Venereol 2010;90:147-151.

3 Krueger G, Koo J, Lebwohl M, Menter A, Stern RS, Rolstad T: The impact of psoriasis on quality of life: results of a 1998 National Psoriasis Foundation patient-membership survey. Arch Dermaology 2001;137:280284.

4 Augustin M, Krüger K, Radtke MA, Schwippl I, Reich K: Disease severity, quality of life and health care in plaque-type psoriasis: a multicenter prospective cross-sectional study in Germany. Dermatology 2008;216: 366-372.

5 Henseler T, Christophers E: Disease concomitance in psoriasis. J Am Acad Dermatol 1995;32:982-986.
6 Taylor W, Gladman D, Helliwell P, Marchesoni A, Mease P, Mielants H; CASPAR Study Group: Classification criteria for psoriatic arthritis: development of new criteria from a large international study. Arthritis Rheum 2006;54:2665-2673.

7 Alamanos Y, Voulgari PV, Drosos AA: Incidence and prevalence of psoriatic arthritis: a systematic review. J Rheumatol 2008;35: 1354-1358.

8 Reich K, Krüger K, Mössner R, Augustin M: Epidemiology and clinical pattern of psoriatic arthritis in Germany: a prospective interdisciplinary epidemiological study of 1,511 patients with plaque-type psoriasis. $\mathrm{Br}$ J Dermatol 2009;160:1040-1047.

9 Radtke MA, Reich K, Blome C, Rustenbach $S$, Augustin M: Prevalence and clinical features of psoriatic arthritis and joint complaints in 2,009 patients with psoriais: results of a German national survey. J Eur Acad Dermatol Venereol 2009;23:683-691.
10 Sterry W, Strober BE, Menter A; on behalf of the International Psoriasis Council: Obesity in psoriasis: the metabolic, clinical and therapeutic implications. Report of an interdisciplinary conference and review. Br J Dermatol 2007; 157:649-655.

11 Farber EM, Nall L: Nail psoriasis. Cutis 1992; 50:174-178.

12 Van Laborde S, Scher RK: Developments in the treatment of nail psoriasis, melanonychia striata, and onychomycosis. Dermatol Clin 2000;18:37-46.

13 Augustin M, Reich K, Blome C, Schäfer I, Laass A, Radtke MA: Nail psoriasis in Germany: Epidemiology and burden of disease. Br J Dermatol 2010, Epub ahead of print.

14 Rich P, Griffiths CEM, Reich K, Nestle FO, Scher RK, Li S, Xu S, Hsu MC, Guzzo C: Baseline nail disease in patients with moderate to severe psoriasis and response to treatment with infliximab during 1 year. J Am Acad Dermatol 2008;58:224-231.

15 Baran RL: A nail psoriasis severity index. $\mathrm{Br}$ J Dermatol 2004;150:568-569. 
16 Cannavò SP, Guarneri F, Vaccaro M, Borgia F, Guarneri B: Treatment of psoriatic nails with topical cyclosporin: a prospective, randomized placebo-controlled study. Dermatology 2003;206:153-156.

17 Ortonne JP, Baran R, Corvest M, Schmitt C, Voisard JJ, Taieb C: Development and validation of nail psoriasis quality of life scale (NPQ10). J Eur Acad Dermatol Venereol 2010;24:22-27.

18 Rich P, Scher RK: Nail Psoriasis Severity Index: a useful tool for evaluation of nail psoriasis. J Am Acad Dermatol 2003;49:206212.

19 Lawry M: Biological therapy and nail psoriasis. Dermatol Ther 2007;20:60-67.
20 Kacar N, Ergin S, Erdogan BS: The comparison of Nail Psoriasis Severity Index with a less time-consuming qualitative system. J Eur Acad Dermatol Venereol 2008;22:219222.

21 Cassell SE, Bieber JD, Rich P, Tutuncu ZN, Lee SJ, Kalunian KC, Wu CW, Kavanaugh A: The modified Nail Psoriasis Severity Index: validation of an instrument to assess psoriatic nail involvement in patients with psoriatic arthritis. J Rheumatol 2007;34:123-129.

22 Aktan S, Ilknur T, Akin C, Ozkan S: Interobserver reliability of the Nail Psoriasis Severity Index. Clin Exp Dermatol 2007;32:141144.

23 Gupta AK, Cooper EA: Psoriatic nail disease: quality of life and treatment. J Cutan Med Surg 2009;13(suppl 2):S102-S106.
24 Drummond MF, O'Brien BJ, Stoddart GL, Torrance GW: Methods for the Economic Evaluation of Health Care Programmes, ed 2. Oxford, Oxford Medical Publications, 1997.

25 Kerkmann U, Winkelman W, Wang Y, Reich $\mathrm{K}$ : Target nail NAPSI correlates with number of nails involved: a clinically efficient, useful, and precise assessment for nail psoriasis severity (poster). Presented at the 18th Congress of the European Academy of Dermatology and Venereology, 7-11 October 2009, Berlin, Germany, poster 1164

26 Augustin M, Amon U, Braathen L, Bullinger M, Gieler U, Klein GF, Schultz-Amling W: Assessment of quality of life in dermatology (German national guideline). J Dtsch Dermatol Ges 2004;9:802-806. 